\title{
Brucella melitensis
}

National Cancer Institute

\section{Source}

National Cancer Institute. Brucella melitensis. NCI Thesaurus. Code C86218.

A species of aerobic, Gram-negative, coccobacilli shaped bacteria assigned to the phylum Proteobacteria. This species is nonmotile, non-spore forming, catalase, oxidase and urease positive, reduces nitrates, does not produce hydrogen sulfide, grows in both basic fuchsin and thionine, and is negative for Tiblisi and Weybridge phage lysis. B. melitensis is found in goats and sheep and is pathogenic to these species as well as causes brucellosis in humans. 